\title{
ІННОВАЦЙНІ ІНФОРМАЦІЙНІ ТЕХНОЛОГІЇ У НАВЧАННІ МАТЕМАТИЧНИХ ДИСЦИПЛІН
}

Лазар В.Ф., Шкирта I.М.

\section{INNOVATIVE INFORMATION TECHNOLOGIES IN THE TEACHING OF MATHEMATICAL}

Lazar Vasyl, Shkyrta Ihor

У статті розглянуто питання, пов'язані $з$ використанням інноваційних інформаційних технологій у навчанні математичних дисциплін, зокрема вільно поширюваних wеb-орієнтованих систем комп'ютерної математики $i$ технологій мобільного навчання математики.

Ключові слова: математичні дисиипліни, жеb-орієнтовані системи комп'ютерної математики, мобільні математичні середовища.

Considered issues related to the use of innovative information technology in learning mathematics, particularly open source web-oriented computer systems and mobile technology learning mathematics.

Wide spectrum of analytical, calculable and graphicoperations, that is supported in moder $n$ mathematicalpackages, in particular and webof CKM, do them one ofbasic instruments in professional activity of mathematician-analyst, engineer, cybernetic economist engineer andothers like that. Therefore their use in the educational process of INSTITUTION of higher learning at the study of mathematical disciplines will give possibility to promote thelevel of professional preparation of students, level themmathematical and informative culture, to do futurespecialists competitive at the international market of labour.

Today can provide access technology of mobile studies tothe wide circle of informative reso urces from a help inexecution concrete work and autonomous educationalcourses that is loaded on the mobile device of student, tothe fully network educational courses with problem oriented,in partic ular and by mathematical, software that is executedon a server on the basis of cloudy

Key words: mathematical discipline, web-oriented computer mathematical system, mobile ICT, mobile math environment.

Математика і вища математична освіта в сучасних умовах відіграють особливу роль у підготовці майбутніх фахівців у галузі математики, інформатики, комп'ютерних та інформаційних технологій, техніки, виробництва, економіки, управління як у плані формування певного рівня математичної культури, інтелектуального розвитку, так і в плані формування наукового світогляду, розуміння сутності практичної спрямованості математичних дисциплін, оволодіння методами математичного моделювання. При цьому рівень цієї підготовки повинен надати можливість студентам у майбутньому створювати $\mathrm{i}$ впроваджувати нові технології, теоретична база яких може бути ще не розробленою під час навчання.

Разом 3 тим у математичній освіті сьогодні накопичилося багато проблем та негативних тенденцій, серед яких можна назвати різке зниження рівня математичної культури сучасної молоді, їх пізнавальної активності і самостійності [1]. Це негативно відбивається на якості знань і умінь студентів ВН3, їх інтелектуальному розвиткові, рівні фахової підготовки.

Практично всі дослідники проблем математичної освіти зазначають, що для подолання негативних явищ в умовах інформаційного суспільства інформаційно- 
комунікаційні технології та інноваційні педагогічні технології повинні стати основою перспективних методичних систем навчання математичних дисциплін. Зокрема, Конрад Вольфрам у своїй лекції “Як навчати дітей справжній математиці за допомогою комп”ютера" у липні 2010 р. зазначає [2]: "У нас великі проблеми з математичною освітою. По суті ніхто не задоволений. Тi, хто вивчає математику, вважають, що вона ніяк не пов'язана з реальним життям, нецікава і складна у навчанні. Ті, хто намагається взяти їх на роботу, вважають, що їхніх знань недостатньо. Уряди розуміють, що це велика проблема для економіки, але не уявляють, як це виправити. Вчителі теж розгублені. I це при тому, що математика ще важливіша для людства сьогодні, ніж будь-коли. Отже, з одного боку ми бачимо падіння інтересу до математики і математичної освіти, а 3 іншого боку, ми живемо в більш математизованому світі, більш кількісному світі, ніж будь-коли. У чому ж проблема, чому раптом з'явилась така прірва, і що можна зробити, щоб це виправити? Насправді, ми думаємо, що відповідь знаходиться перед нами. Використовуйте комп'ютери. Ми вважаємо, що правильне використання комп'ютерів - це чарівний засіб змусити працювати математичну освіту" (переклад автора).

Враховуючи сказане, актуальною $є$ проблема обгрунтування, створення та широке впровадження в повсякденну педагогічну практику інноваційних інформаційнокомунікаційних технологій навчання математичних дисииллін у ВНЗ, використання яких надасть можливість активізувати навчально-пізнавальну i науково-дослідну діяльність студентів, підвищити рівень їхньої математичної і професійної підготовки, розкрити творчий потенціал і збільшити роль самостійної та індивідуальної роботи за рахунок застосування новітніх інформаційних та педагогічних технологій.

Аналізу зазначеної проблеми і деяким шляхам ії вирішення присвячені роботи В.В. Корольського, Т.Г. Крамаренко, С.О. Семерікова, С.В. Шокалюк [3], Н.В. Рашевської [4], С.О. Семерікова [5], К.І. Словак [6].

Завдання статті: розкрити сутність таких понять, як інноваційні інформаційнокомунікаційні технології навчання, web-орієнтовані системи комп'ютерної математики, мобільні інформаційно-комунікаційні технології навчання математики, мобільні математичні середовища, дати загальну характеристику зазначених технологій i середовищ, а також визначити їх роль і місце у створенні методичних систем навчання математичних дисциплін у BH3.

Під інноваційними інформачійно-комунікаційними технологіями навчання розумітимемо нові, оригінальні технології (методи, засоби, способи) створення, передавання $\mathrm{i}$ збереження навчальних матеріалів, інших інформаційних ресурсів освітнього призначення, а також технології організації і супроводу навчального процесу (традиційного, електронного, дистанційного, мобільного) за допомогою телекомунікаційного зв'язку і комп'ютерних мереж, що цілеспрямовано, систематично й послідовно впроваджуються в освітню практику.

До таких технологій навчання математичних дисциплін, на думку авторів, належать: web-орієнтовані системи комп'ютерної математики;

мобільні інформаційно-комунікаційні технології навчання математики; мобільні математичні середовища.

Дамо стислу характеристику зазначених інноваційних IКТ навчання математики.

Web-оріснтовані системи комп'ютерної математики. У зв'язку 3 широким використанням у навчальному процесі вищої школи мережі Internet та іï ресурсів, зокрема технологій Web 2.0, вільно поширюваного програмного забезпечення для електронного, дистанційного і мобільного навчання, систем комп'ютерної математики (СКМ), актуальною $\epsilon$ проблема створення web-орієнтованих навчально-методичних комплексів математичних дисциплін. Одним з шляхів вирішення цієї проблеми є використання web-орієнтованих версій систем комп'ютерної математики (Matlab Web Server, webMathematica, wxMaxima) та їx інтеграція одна з однією та 3 іншими програмними продуктами. Прикладом такої інтеграції $\epsilon$ web-орієнтована СКМ SAGE (Software for Algebra and Geometry Experimentation) - вільно 
поширювана система для виконання символьних, алгебраїчних і чисельних розрахунків та графічних побудов, інтерфейс якої написаний потужною мовою програмування Python, i яка інтегрується як 3 комерційними СКМ (Maple, Mathematica, Matlab), так і 3 вільно поширюваними CKM (Skilab, Maxima, Octave та ін.). SAGE об'єднав можливості популярних вільно поширюваних математичних програм та бібліотек, таких як PARI, GAP, GSL, Singular, MWRANK, NetworkX, Maxima, Sympy, GMP, Numpy, mathplotlib та багатьох інших засобами Python, Lisp, Fortran 95 та $\mathrm{C} / \mathrm{C}++$. Крім того, SAGE може інтегруватися із системами електронного навчання (наприклад, Moodle), що $є$ доволі важливим для створення webорієнтованих освітньо-наукових інформаційних середовищ i web-орієнтованих методичних систем навчання математичних дисциплін [3].

До інноваційних web-орієнтованих IKT навчання математики можна віднести систему Wolfram|Alpha - база знань та набір обчислювальних алгоритмів (англ. computational knowledge engine (CKE)). Wolfram|Alpha заснована на обробці природної мови (зараз англійської), величезній бібліотеці алгоритмів і NKS (New Kind of Science) - підході для знаходження відповідей на запити. Система написана мовою Mathematica i становить близько 8 міліонів рядків, що зараз виконуються приблизно на 10000 процесорах. Wolfram|Alpha не повертає перелік посилань, заснований на результатах запиту, а обраховує відповідь, використовуючи власну базу знань, яка містить відомості про математику, інформатику, фізику, астрономію, хімію, біологію, медицину, історію, географію, політику, музику, кінематографію, а також інформацію про відомих людей та інтернет-сайти.

Програмний продукт здатний переводити дані в різні одиниці вимірювання, системи числення, добирати загальну формулу послідовності, знаходити можливі замкнені форми для наближених дробових чисел, обраховувати суми, границі, похідні, інтеграли, розв'язувати рівняння і системи рівнянь, виконувати операції з матрицями, визначати властивості чисел і геометричних фігур, виконувати логічні операції, будувати нормальні форми для формул логіки предикатів, виконувати і візуалізувати операції над множинами, шукати екстремуми функцій однієї і багатьох змінних, будувати графіки функцій, заданих у різних формах i координатах і т.д.

У жовтні 2009 р. було випущено програмний продукт для iPhone (пізніше - для iPad), а у жовтні 2010 р. - для Android, що являє собою браузер, здатний показувати лише одну сторінку - m.wolframalpha.com 3 розширеною клавіатурою для введення математичних формул. Це дає можливість використовувати Wolfram|Alpha як програмний засіб мобільного навчання математики.

Мобільні інформаційно-комунікаційні технології навчання математики. Серед існуючих ІКТ та засобів навчання найсприятливішими для реалізації навчання вищій математиці за змішаною моделлю є мобільні інформаційно-комунікаційні технології.

Мобільними інформаџійно-комунікаційними технологіями навчання називатимемо сукупність мобільних апаратних та програмних засобів, а також систему методів та форм використання таких засобів у навчальному процесі 3 метою отримання, збереження, опрацювання та відтворення аудіо-, відео-, текстових, графічних та мультимедіа даних в умовах оперативної комунікації з глобальними та локальними ресурсами [4].

Введення мобільних ІКТ до складу методичних систем навчання математичних дисциплін у ВНЗ змінює усі ії складові, проте найбільшою мірою - технологічну підсистему методичної системи навчання (засоби, методи форми навчання).

Провідними засобами навчання математичних дисциплін стають мобільні засоби загального та спеціального призначення: апаратні (мобільні телефони, смартфони, електронні книжки, ноутбуки і нетбуки, кишенькові ПК, планшети тощо) та програмні (мобільні системи підтримки навчання, мобільні педагогічні програмні засоби, системи зворотного зв’язку, мобільні системи комп’ютерної алгебри та динамічної геометрії).

Як мобільний програмний засіб навчання вищої математики можна використовувати нову систему MathPiper [4], що інтегрує в собі систему комп'ютерної алгебри Yacas та 
систему динамічної геометрії GeoGebra.

MathPiper - це нова математично-орієнтована мова програмування, яка, з одного боку, доволі проста, з іншого боку - доволі потужна, щоб бути корисною для розв'язання широкого класу математичних та інженерних задач (www.mathpiper.org). MathPiper також $\epsilon$ системою комп'ютерної алгебри (CAS). Крім того, для програмування під MathPiper використовується інтегроване середовище розробки (IDE) MathPiperIDE, що містить потужні засоби редагування тексту та інтерактивної графіки.

GeoGebra - вільно поширювана система комп'ютерної геометрії (CGS), яка дає можливість створювати “живі креслення” для використання в геометрії, алгебрі, планіметрії, зокрема, для побудов за допомогою циркуля і лінійки. Крім того, програма надає широкі можливості для роботи з функціями (побудова графіків, обчислення коренів, екстремумів, інтегралів і т. д.) за рахунок команд вбудованої мови, використовуючи яку можна керувати i геометричними побудовами. У таблиці 1 наведено деякі характеристики розглянутих вище web-орієнтованих СКМ.

Таблиця 1

Загальна характеристика деяких wеb-оріснтованих СКМ

\begin{tabular}{|l|l|l|l|l|}
\hline $\begin{array}{l}\text { Характерис- } \\
\text { тика ПЗ }\end{array}$ & Sage & GeoGebra & MathPiper & Wolfram|Alpha \\
\hline Тип ПЗ & CAS & CGS & CAS & CKE \\
\hline $\begin{array}{l}\text { Мова } \\
\text { розробки }\end{array}$ & Python & Java & Java & Mathematica \\
\hline Розробник & William Arthur Stein & Markus Hohenwarter & $\begin{array}{l}\text { Ted Kosan } \\
\text { Grzegorz Mazur } \\
\text { Sherm Ostrowsky }\end{array}$ & Stephen Wolfram \\
\hline $\begin{array}{l}\text { Операційні } \\
\text { системи }\end{array}$ & Cross-platform & Cross-platform & $\begin{array}{l}\text { Linux, Windows, } \\
\text { Mac }\end{array}$ & Cross-platform \\
\hline $\begin{array}{l}\text { Ліцензія } \\
\text { GNU GPL }\end{array}$ & GNU GPL & GNU & $\begin{array}{l}\text { Commercial (але доступ } \\
\text { вільний ) }\end{array}$ \\
\hline $\begin{array}{l}\text { Рік випуску } \\
\text { першої версії }\end{array}$ & 2005 p. & 2009 p. & 2009 p. & 2009 p. \\
\hline Сайт & www.sagemath.org & www.geogebra.org & www.mathpiper.org & www.wolframalpha.com \\
\hline
\end{tabular}

Мобільні математичні середовища. Сьогодні можливість навчання будь-де і будьколи $є$ загальною тенденцією інтенсифікації життя в інформаційному суспільстві. Така можливість забезпечується, зокрема, й за допомогою так званого мобільного навчання - нової технології навчання, що грунтується на інтенсивному застосуванні сучасних мобільних засобів та технологій [5]. Мобільне навчання є новою освітньою парадигмою, на основі якої створюється нове навчальне середовище, де студенти можуть отримати доступ до навчальних матеріалів у будь-який час та в будь-якому місці, що робить процес навчання привабливішим, демократичним і стимулює студента до самоосвіти та навчання протягом усього життя.

Мобільне математичне середовище (MМC) можна визначити як відкрите модульне мережне мобільне інформаційно-обчислювальне програмне забезпечення, що надає користувачу (викладачу, студенту) можливість мобільного доступу до інформаційних ресурсів математичного і навчального призначення, створюючи умови для ефективної організації навчального процесу та інтеграції аудиторної і позааудиторної роботи [6, 7].

Основними складовими MMC є обчислювальне ядро (web-CKM), інформаційне i методичне забезпечення (лекційні демонстрації, презентації та інші навчальні матеріали в електронному вигляді, тренажери, динамічні математичні моделі, навчальні експертні системи), а також мережний сервер.

Головними критеріями вибору СКМ для обчислювального ядра ММС є [8]:

- розширюваність (система повинна надавати можливість користувачеві доповнювати ії для розв'язання нових класів задач); 
- наявність різних інтерфейсів та підтримка web-сервісів (для забезпечення мобільного доступу);

- кросплатформеність (мобільність програмного забезпечення);

- можливість створення програм із стандартними елементами управління (лекційних демонстрацій, динамічних моделей, тренажерів, навчальних експертних систем);

- можливість інтегрувати у себе різноманітне програмне забезпечення (на основі відкритих програмних інтерфейсів);

- підтримка технологіï Wiki;

- можливість локалізації та вільне поширення.

- Зокрема як обчислювальне ядро ММС можна використовувати web-CKM SAGE [6], яка задовольняє практично всі зазначені вимоги.

До основних характеристик ММС належать $[6,7]$ :

- мобільність доступу: виконуваність на широкому спектрі комп'ютерних пристроїв, що надає можливість залучити як засоби навчання нетбуки, планшетні комп’ютери та смартфони;

- мобільність програмного забезпечення: можливість перенесення середовища на різні програмно-апаратні платформи без значної модифікації;

- мережність: використання і зберігання математичних об'єктів на мережних серверах, що надає можливість уніфікувати доступ до них як в навчальній аудиторії, так і за іiі межами;

- відкритість: можливість зміни інформаційної та обчислювальної складових середовища;

- модульність: можливість додавання, вилучення та заміни компонентів середовища;

- об'єктна орієнтованість: можливість прототипування, створення, модифікації, наслідування, інкапсуляції математичних об’єктів;

- можливість застосування ефективних педагогічних технологій організації роботи студентів над навчальними і дослідницькими проектами у навчальних спільнотах.

Особливістю ММС є динамічна природа навчальних матеріалів - будь-який опублікований у мережі об'єкт може автоматично змінюватися відповідно до: зміни вмісту пов'язаного з ним робочого аркуша; зміни програмного забезпечення, що входить до складу MMC; зміни пристрою доступу до навчальних матеріалів; зміни початкових умов для моделей.

1. Широкий спектр аналітичних, обчислювальних і графічних операцій, що підтримується в сучасних математичних пакетах, зокрема й web-CKM, роблять їх одними 3 основних інструментів у професійній діяльності математика-аналітика, інженера, економістакібернетика тощо. Тому їх використання у навчальному процесі ВН3 при вивченні математичних дисциплін надасть можливість підвищити рівень професійної підготовки студентів, рівень їх математичної та інформаційної культури, зробити майбутніх фахівців конкурентноспроможними на міжнародному ринку праці.

2. Технології мобільного навчання сьогодні можуть забезпечувати доступ до широкого кола інформаційних ресурсів - від допомоги у виконанні конкретної роботи та автономних навчальних курсів, що завантажуються на мобільний пристрій студента, до повністю мережних навчальних курсів з проблемно орієнтованим, зокрема й математичним, програмним забезпеченням, що виконується на сервері на основі хмарних технологій.

3. Перспективними напрямами розвитку методики використання MMC є: розроблення ММС з математичних дисциплін для студентів ВН3 з урахуванням професійної спрямованості навчання; розроблення методики використання засобів ММС у процесі навчально-дослідницької роботи студентів: підготовка конкурсних, курсових, кваліфікаційних робіт, бакалавра, спеціаліста, магістра.

4. Методичні системи навчання всіх дисциплін, зокрема й математичних, повинні розроблятися на основі інноваційних педагогічних та інформаційно-комунікаційних 
технологій, використання яких може забезпечити створення у ВНЗ єдиного освітньонаукового інформаційного середовища, в якому навчальна діяльність студентів буде своєрідною моделлю їх майбутньої професійної діяльності в умовах інформаційного суспільства.

\section{Список використаних джерел}

1. Триус Ю.В. Комп’ютерно-орієнтовані методичні системи навчання математики: монографія. - Черкаси: Брама-Україна, 2005. - 400 с.

2. Conrad Wolfram: Teaching kids real math with computers: [Electronic resource]. - Режим доступу: http://www.ted.com/talks/lang/eng/ conrad_ wolfram_teaching_kids_real_math_with_computers. html.

3. Інноваційні інформаційно-комунікаційні технології навчання математики : навчальний посібник / В.В. Корольський, Т.Г. Крамаренко, С.О. Семеріков, С.В. Шокалюк; науковий редактор академік АПН України, д.пед.н., проф. М.І. Жалдак. - Кривий Ріг : Книжкове видавництво Кирєєвського, 2009. - 324 с.

4. Рашевська Н. В. Мобільні інформаційно-комунікаційні технології навчання вищої математики студентів вищих технічних навчальних закладів: автореф. дис. ... канд. пед. наук: 13.00.10 - інформаційно-комунікаційні технології в освіт / Н.В. Рашевська; Інститут інформаційних технологій і засобів навчання НАПН України. - К., 2011. $-21 \mathrm{c}$.

5. Семеріков С.О. Фундаменталізація навчання інформатичних дисциплін у вищій школі: [монографія] / Науковий редактор академік АПН України, д.пед.н., проф. М.І. Жалдак. - К.: НПУ ім. М.П. Драгоманова, 2009. - 340 с.

6. Словак К.І. Теорія та методика застосування мобільних математичних середовищ у процесі навчання вищої математики студентів економічних спеціальностей [Електронний ресурс] / С.О. Семеріков, К.І. Словак // Інформаційні технології і засоби навчання. - 2011. - №1(21). - Режим доступу: http://journal.iitta.gov.ua.

7. Словак К. І. Методика використання мобільних математичних середовищ у процесі навчання математики студентів економічних ВНЗ: автореф. дис. ... канд. пед. наук: 13.00.10 - інформаційно-комунікаційні технології в освіт / К.І. Словак; Інститут інформаційних технологій і засобів навчання НАПН України. - К., 2011. - 21 с.

8. Словак К.І., Семеріков С.О., Триус Ю.В. Мобільні математичні середовища: сучасний стан та перспективи розвитку // Науковий часопис НПУ імені М. П. Драгоманова. Серія 2. Комп'ютерно-орієнтовані системи навчання: зб. наук. праць. - К.: НПУ ім. М. П. Драгоманова, 2012. - №12(19). - С. 102-109.

\section{References}

1. Tryus Yu.V. 2005. Komp'yuterno-oriyentovani metodychni systemy navchannya matematyky [Computer-aided methodical systems for teaching mathematics]. Cherkasy: Brama-Ukraine.

2. Conrad Wolfram: Teaching kids real math with computers. [online] Available at: http://www.ted.com/talks/lang/eng/conrad wolfram teaching kids real math with comput ers.html.

3. Korol's'kyy, V.V., Kramarenko, T.H., Semerikov, S.O., Shokalyuk, S.V.; Zhaldak, M.I. ed., 2009. Innovatsiyni informatsiyno-komunikatsiyni tekhnolohiyi navchannya matematyky [Innovative information and communication technologies of mathematics teaching]. Kryvyi Rih: Kireevsky Book Publishing House.

4. Rashevs'ka, N. V. 2011. Mobil'ni informatsiyno-komunikatsiyni tekhnolohiyi navchannya vyshchoyi matematyky studentiv vyshchykh tekhnichnykh navchal'nykh zakladiv [Mobile information and communication technologies of higher mathematics education of students of higher technical educational establishments]. Abstract of dissertation. Candidate of 
Pedagogical Sciences. Institute of Information Technologies and Teaching Aids of NAPS of Ukraine.

5. Semerikov, S.O.; Zhaldak, M.I. ed., 2009. Fundamentalizatsiya navchannya informatychnykh dystsyplin $u$ vyshchiy shkoli [Fundamentalisation of higher education education in computer science]. Kiev: M.P. Drahomanov.

6. Slovak, K.I., Semerikov, S.O. 2011. Teoriya ta metodyka zastosuvannya mobil'nykh matematychnykh seredovyshch $u$ protsesi navchannya vyshchoyi matematyky studentiv ekonomichnykh spetsial'nostey [Theory and methodology of application of mobile mathematical environments in the process of teaching higher mathematics students of economic specialties]. Information technology and teaching aids, 1(21). [online] Available at: http://journal.iitta.gov.ua.

7. Slovak, K. I. 2011. Metodyka vykorystannya mobil'nykh matematychnykh seredovyshch $u$ protsesi navchannya matematyky studentiv ekonomichnykh VNZ [Methods of using mobile mathematical environments in the process of teaching mathematics students of economic universities]. Abstract of dissertation. Candidate of Pedagogical Sciences. Institute of Information Technologies and Teaching Aids of NAPS of Ukraine.

8. Slovak, K.I., Semerikov, S.O., Tryus, Yu.V. 2012. Mobil'ni matematychni seredovyshcha: suchasnyy stan ta perspektyvy rozvytku [Mobile Mathematical Environments: Current State and Prospects for Development]. Scientific journal of M.P Dragomanov NPU. Series 2. Computer-based learning systems,12(19), pp. 102-109.

УДК 338.48-44(23.0)(477.8)(045)

DOI:10.31339/2617-0833-2019-2(27)-2-28-34

\section{A KÁRPATALJA REGIONÁLIS REKREÁCIÓS VONZÁSÁNAK SZOCIO- FÖLDRAJZI LEHETŐSÉGEI A FENNTARTHATÓ FEJLŐDÉS ÖSSYEFÜGGÉSÉBEN} Mashika G., Luzhanskaya T., Movchan K., Derkach V.

\section{СУСПІЛЬНО-ГЕОГРАФІЧНИЙ ПОТЕНЦАЛ РЕКРЕАЦЙНОӤ ПРИВАБЛИВОСТІ КАРПАТСЬКОГО РЕГІОНУ В КОНТЕКСТІ СТІЙКОГО РОЗВИТкУ}

Машіка Г.В. Лужанська Т.Ю., Мовчан К.М., Деркач В.Ю.

\section{SOCIO-GEOGRAPHICAL POTENTIAL OF RECREATIONAL ATTRACTIVENESS OF THE CARPATHIAN REGION IN THE CONTEXT OF SUSTAINABLE DEVELOPMENT}

Mashika Anna, Luzhanskaya Tetyana, Movchan Katerina, Derkach Victoria

A kutatási téma relevanciája annak a ténynek köszönhetö, hogy a hatékony kiválasztáshoz és a területfejlesztés optimális stratégiájához figyelembe kell venni a Kárpát-vidék természetiföldrajzi, geopolitikai, történelmi-kulturális, gazdasági jellemzöit. A Kárpátok régió Ukrajna egyik legvonzóbb és leggazdagabb természeti eröforrása. Ezért az egyedülálló rekreációs és földrajzi helyzet miatt aktualizálódott az ökológiai szempontból megalapozott határokon belüli rekreációs igény, amely aktív formája lehet a Kárpátok ökológiai biztonságának biztosításában. A tanulmány célja a Kárpát-régió rekreációs vonzerejének lehetöségeinek szisztematikus társadalmi-földrajzi értékelése annak a stratégiának a javitása érdekében, amelynek célja a régió átalakitása a fenntartható turizmus egyikfö központjává.

A rekreációs vonzerö potenciáljának meghatározására szolgáló modell figyelembe veszi a meglévö turisztikai és közlekedési infrastruktúrát, szezonális összetevijét, valamint a turista számára rendelkezésre álló rekreációs és rekreációs típusokat. A tanulmány eredményeinek megszerzéséhez a 